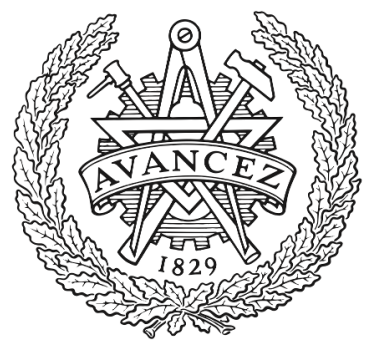

CHALMERS

UNIVERSITY OF TECHNOLOGY

\title{
A design navigator to guide the transition towards environmentally benign product/service systems based on LCA results
}

Downloaded from: https://research.chalmers.se, 2023-04-26 13:26 UTC

Citation for the original published paper (version of record):

Neramballi, A., Sakao, T., Willskytt, S. et al (2020). A design navigator to guide the transition towards environmentally benign product/service systems based on LCA results. Journal of Cleaner Production, 277: 124074-. http://dx.doi.org/10.1016/j.jclepro.2020.124074

N.B. When citing this work, cite the original published paper. 


\title{
A design navigator to guide the transition towards environmentally benign product/service systems based on LCA results
}

\author{
Abhijna Neramballi ${ }^{a,}{ }^{*}$, Tomohiko Sakao ${ }^{a}$, Siri Willskytt ${ }^{\mathrm{b}}$, Anne-Marie Tillman ${ }^{\mathrm{b}}$ \\ ${ }^{a}$ Division of Environmental Technology and Management, Department of Management and Engineering, Linköping University, SE, 58183, Linköping, \\ Sweden \\ ${ }^{\mathrm{b}}$ Division of Environmental Systems Analysis, Department of Technology Management and Economics, Chalmers University of Technology, S, 412 96, \\ Gothenburg, Sweden
}

\section{A R T I C L E I N F O}

\section{Article history:}

Received 3 September 2019

Received in revised form

25 August 2020

Accepted 1 September 2020

Available online 7 September 2020

Handling editor: Yutao Wang

\section{Keywords:}

Product/service systems

Design navigator

Design method

Circular economy

Lifecycle perspective

Life cycle assessment

\begin{abstract}
A B S T R A C T
With rising societal demands for a transition towards a circular economy and intensifying market competition, manufacturing companies are increasingly seeking alternative ways to design and develop their industrial offerings with reduced environmental impacts and increased value. A possible solution lies in designing environmentally benign product/service systems (PSSs), which often requires the redesign of existing offerings in industrial practice.

This article presents a design navigator named lifecycle-oriented function deployment (LFD), which builds on the widely utilized life cycle assessment (LCA) and quality function deployment (QFD) to support the redesign of existing industrial offerings towards PSSs with reduced environmental impacts. LFD includes a novel procedure to derive environmental requirements using LCA and to prioritize them along with customer requirements. It introduces a list of generic service design characteristics to support service design. It also contains a QFD-based procedure to identify design parameters (characteristics and components for both products and services) that have a relatively strong influence on the prioritized requirements. Further, a novel way is proposed to capture specific product and service design characteristics that are feasible to integrate and potentially have a rather strong influence on the requirements when combined.

LFD is subsequently applied in a case study to conceptually redesign an existing offering in a manufacturing company. The application is then assessed using an LCA and a semi-structured interview with the users of LFD. The LCA results indicate significant reductions in environmental impacts of the redesigned concepts, and the interview revealed benefits for the practitioners who used LFD.
\end{abstract}

(C) 2020 Elsevier Ltd. All rights reserved.

\section{Introduction}

Over the last few decades, manufacturing companies have faced the challenge of lowering the environmental impacts of their products from a lifecycle perspective (Alting and Legarth, 1995; Ramani et al., 2010). This challenge has been escalating with our societies' increasing interest in the transition towards a circular economy (CE), "which is restorative by design, and aims to keep

Abbreviations: List of acronyms, LCA; (life cycle assessment), QFD; (quality function deployment), PSS; (product/service system), LFD; (lifecycle-oriented function deployment), EO; (existing offering), RO (redesigned offering).

* Corresponding author. , .

E-mail addresses: abhijna.neramballi@liu.se, abhijna.19@gmail.com (A. Neramballi). products, components and materials at their highest utility and value, at all times" (Webster, 2015). The challenge accumulates on top of the need for constantly improving the marketability and competitiveness of the offerings (Tukker, 2015). Addressing these challenges simultaneously is highly demanding but crucial for the companies.

A product/service system (PSS), defined as "a mix of tangible products and intangible services, designed and combined so that they jointly are capable of fulfilling final customer needs" (Tukker and Tischner, 2006) has been heralded as one of the most effective instruments for addressing the aforementioned challenges 
(Tukker, 2015). Despite its envisioned potential, all transitions to PSSs are not necessarily environmentally benign (Tukker, 2004). Therefore, supporting companies to design PSSs with comparatively less environmental impacts (than existing industrial offerings ${ }^{1}$ ) is important. In industrial practice, redesign is significant, since most design solutions evolve from existing models ( $\mathrm{Li}$ and Chen, 2010). Thus, supporting manufacturing companies in the redesign of their existing design objects towards PSSs with comparatively less environmental impacts is crucial.

Life cycle assessment (LCA) (ISO, 2006), a rigorous method used for calculating environmental impacts generated over a product lifecycle, is widely acknowledged and used in industry. It can be used in redesign, as it highlights the environmental impacts of a design object with quantitative figures (Muñoz et al., 2009). Earlier research reports concrete cases of using LCA results to redesign products without a pre-defined procedure (Lacasa et al., 2016; Muñoz et al., 2009) and a number of methods for designing products using LCA results (Ramani et al., 2010). An LCA based approach has also been used in a specific case of PSS design in industry (Fargnoli et al., 2018). Although a few such works (see also, e.g., Lelah et al., 2011) have previously exploited the potential of LCA to support PSS design, the process of translating LCA results into actionable insights for PSS designing remains a black or grey box and tends to be case-specific. This issue points towards a lack of transparent and generic support for practitioners to navigate the redesign of an existing industrial offering towards a PSS with decreased environmental impacts, by systematically utilizing the results of its LCA. This type of support will be of significance due to the expectation for wide adoption by designers in manufacturing companies.

The objective of this article is to provide manufacturing companies with a generic and transparent design support to address the prevalent challenges concerning the reduction of environmental impacts and enhancement of the market competitiveness of their offerings. To operationalize this objective, development opportunities related to LCA and PSSs are exploited, and a generic design navigator ${ }^{2}$ named lifecycle-oriented function deployment (LFD) is proposed. This navigator uses the results of LCA of any existing industrial offering to support decision-making in the early phase of its redesign, towards a PSS with reduced environmental impacts. It builds upon earlier works with a combination of quality function deployment (QFD) for a product and LCA (Sakao, 2007) as well as QFD for PSS (Sakao et al., 2009). QFD (Akao, 1990) is adopted because it translates various requirements into design characteristics and components in a systematic manner (Fargnoli and Sakao, 2017) and is one of the most widely used methods in industry (Booker, 2012). Thereafter, the utility of the presented navigator is assessed with a real case in a manufacturing company.

The article is structured as follows. First, Section 2 gives more detail for the motivation of this research based on a review of related works. Next, Section 3 describes the design navigator in detail, while Section 4 provides the details of its application to a real case in industry. Finally, Sections 5 and 6 discuss the research results and present the conclusion and future work, respectively.

\footnotetext{
${ }^{1}$ Existing industrial offerings refer to products, services or product/service systems offered to customers at present.

2 "Design navigator" is introduced as an alternative to the highly saturated academic term "design method" offered to support the design activities carried out by practitioners. It is described as "a support system to guide the decision making of designers during design or redesign activities, considering the situation of the offering and the designer".
}

\section{Research motivation}

All transitions of industrial offerings to PSS may not necessarily reduce their environmental impacts (Kjaer et al., 2019; Tukker, 2015). Rather, the offerings have to be designed, developed and delivered in specific ways (Vezzoli et al., 2015) to achieve the desired results. Environmental impacts of the offerings are mainly determined during the early stages of design of new offerings (Ramani et al., 2010; Lindahl, 2018) or the redesign of existing offerings. Consequently, designers need to be aware of and responsive to these potential environmental impacts, during the early stages of design or redesign, to develop environmentally benign PSSs. The involved physical products and services of the offering being designed also need to be combined, integrated and optimized as a system from a lifecycle perspective (Lindahl et al., 2014; Lindahl, 2018) to make full use of the potential.

Several definitions of the PSS have been proposed in academia (see Boehm and Thomas, 2013; Tukker, 2015); however, to the best of the authors' knowledge, none of these definitions comprehensively encapsulates the role of design and the lifecycle perspective. Consideration of these aspects during the development of a PSS is crucial to effectively create value for the customers and to mitigate the potential environmental impacts. In order to highlight the importance of consideration of these crucial aspects, PSS is redefined here as " a system consisting of integrated combinations of tangible products and intangible services that is designed from a lifecycle perspective to create value for customers and to reduce its environmental impact" (modified from Tukker and Tischner, 2006; Lindahl et al., 2014). Below, differences in the characteristics of the design of traditional products and PSSs are explained in more detail to highlight the motivation for this research.

The focus of the development of traditional product-centric offerings is mainly on the design of physical elements (Maussang et al., 2009) complemented by the design of any needed service activities (Aurich and Fuchs, 2004). In contrast, the design of PSSs requires consideration of a systems perspective (Manzini and Vezzoli, 2003), and the systematic integration of product and service elements (Aurich et al., 2006; Geum and Park, 2011), partly based on their potential exchangeability (see Sakao and Lindahl, 2015). This brings the required value to the PSS as a system (Baines et al., 2007). On top of the aforementioned characteristics, it requires consideration of a lifecycle perspective (Lindahl et al., 2014) to make informed design decisions in relation to the environmental impacts. Due to these inherent differences in characteristics, PSS development is considered to require specific design approaches (Vezzoli et al., 2015). As a consequence, an increasing number of manufacturing companies are seeking support in the form of dedicated design methods and tools, as they explore the prospect of transitioning to PSSs (Vasantha et al., 2012). A few existing methods provide support for the lifecycle-oriented design of PSSs with consideration of environmental aspects (Aurich et al., 2006; Maxwell et al., 2006; Geum and Park, 2011; Sousa-Zomer and Miguel, 2017). However, none of these methods allow users to quantitatively reflect on the environmental impacts of an offering being redesigned to a PSS.

LCA can potentially provide the required quantitative information regarding environmental impacts, as illustrated by its extensive application in the ecodesign of products (see Chang et al., 2014). Several previous works have used LCA to support different aspects of the realization of environmentally benign PSSs, including business model aspects. For example, Allais and Gobert (2016), in part, used comparative LCA to analyse the changes introduced by a transition towards a PSS-based business model for the offering of small household appliances in an urban area. Scheepens et al. (2016), in turn, applied an LCA based eco-costs value ratio model 
to support the analysis, development and implementation of PSSbased business models for the offering of sustainable water recreation. Zhang et al. (2018) proposed an evaluation approach that utilizes LCA, in part, to support the analysis, assessment and selection of sustainable alternatives of PSS "modes" for the offering of high-energy-consuming equipment.

A few other past works have indicated (e.g., Bey and McAloone, 2006) and also demonstrated (e.g., Lelah et al., 2011) the potential exploitability of LCA in PSS design without showing a generic and operational design procedure. Yet, few other works have proposed or utilized pre-defined LCA-based approaches to support comparative assessments of alternative PSS and/or other design solutions. For example, Amaya et al. (2014) proposed an LCA-based computational approach to support designers in quantifying and comparing the environmental impacts of different PSS design alternatives. Also, Fargnoli et al. (2018) partly utilized an LCA-based approach to simulate and evaluate alternative life-cycle scenarios for a specific case of PSS design in the medical device manufacturing industry.

However, these previous works do not provide a generic and transparent procedural support to translate the information sourced from the LCA of an existing offering, in terms of relevant information that can guide its redesign to an environmentally benign PSS. More specifically, there is a lack of support for PSS designers i) to identify and prioritize relevant environmental design requirements based on the results of the LCA of an existing offering, ii) to elicit rated integral design requirements including environmental and customer requirements, and iii) to prioritize the integration alternatives of specific product and service elements based on the elicited design requirements. This type of support will be useful to make effective design decisions during the development of environmentally benign PSSs.

\section{Description of the design navigator}

\subsection{Overall procedure}

LFD is intended for application in the early stages of the conceptual design of new offerings based on previous generation design objects (existing offerings). The application of the navigator is carried out in four phases, with cyclical iterations, if required. An overview is illustrated in Fig. 1.

The objective of the redesign is to increase value to and meet requirements of customers (or users) by directly addressing their needs and reducing the environmental impact of the existing offering. The existing offering can include both product and service elements, with no restriction on the current level of integration between them. To exploit the full potential of a prospective PSS, these elements need to be redesigned and integrated appropriately from a systems and lifecycle perspective. The involved products or services can have any degree of design maturity. In this research, the design maturity of a design object is considered to be relative to the number of times of previous design.

Application of LFD starts in Phase 0 with the offering being redesigned, termed as existing offering (EO). In this phase, the market research and LCA of the EO are performed to collect the customer needs and assess the current levels of environmental impact, respectively.

This is followed by Phase 1, which utilizes the outcomes of the previous phase to aid the designers in three different aspects: i) elicitation and quantitative-based prioritization of customer and environmental-related requirements, ii) derivation of product and service design characteristics, and iii) semi-quantitative translation of rated requirements into rated product and service design characteristics. The outcomes will indicate the relative impact of specific design characteristics on the rated requirements.
Using these outcomes, Phase 2 will support the translation of these semi-quantitatively rated product and service design characteristics into semi-quantitative ratings for specific product and service components. These outcomes will indicate the relative impact of specific components on the rated requirements. This phase allows the designers to perform an in-depth analytical inspection of specific components of the offering and their relationship to the rated requirements vis-à-vis the rated characteristics.

Phase 3 will also utilize the outcomes of Phase 1 to guide the prioritization for the integration of potentially feasible combinations of product and service design characteristics. This prioritization is based on potential exchangeability and the combined impact on rated design requirements.

The outcomes of the phases $1-3$ collectively form the "hotspots" to be considered for redesign during the proceeding concept generation phase. Phase 0 can be carried out by market and environmental specialists (with, e.g., LCA knowledge) of the company. The remaining phases are recommended to be carried out in a workshop setting, including personnel with the following roles as participants: i) product designer or developer, ii) service designer or developer, iii) environmental specialist, and iv) market specialist. Phases 0 and 1 need to be carried out in sequence, while the rest can be carried out in any order after Phase 1, according to the need for the specific redesign.

\subsection{Phase 0}

This phase has two activities: Activity 0.1. Market research and Activity 0.2. LCA. They can be carried out in parallel. The goal of this phase is to analyse the EO both from customer/market and from the environmental points of view.

\subsubsection{Activity 0.1. Market research}

This activity entails gathering i) market (customer and or user) ${ }^{3}$ feedback regarding the EO and ii) their needs from the RO. The major outcome of this process is customer needs and their expectations from the RO. It can be performed by internal or external marketing specialists. The methods supporting this process are well established in academia and industry (see Akao, 1990; Ulrich and Eppinger, 2012).

\subsubsection{Activity 0.2. LCA}

This activity entails life cycle assessment (LCA) (see Baumann and Tillman, 2004; ISO, 19970, 1997) of the EO. It can be performed by environmental specialists, either internal or external, to the navigator users' company. The major outcome of this activity is information regarding the environmental impact of the EO from the lifecycle perspective.

\subsection{Phase 1 - Prioritization of design characteristics}

Phase 1 has three activities: Activity 1.1. Requirements elicitation and the corresponding quantitative prioritization. The outcomes of Phase 0 will serve as the informational input to this activity; Activity 1.2. Derivation of product and service design characteristics of the EO; Activity 1.3. Co-relation of product and service characteristics of the EO with the rated requirements, to obtain their respective relative impact ratings. A skeletal representation of the QFD-based matrix used in this phase is illustrated in Fig. 2.

\footnotetext{
${ }^{3}$ Customers may refer to the ones who directly pay for the offering, while the users are the ones who use the offering. In most cases, they tend to be the same. Both "customers" and "users" are referred to as "customers" throughout the paper for simplicity unless specifically addressed otherwise.
} 


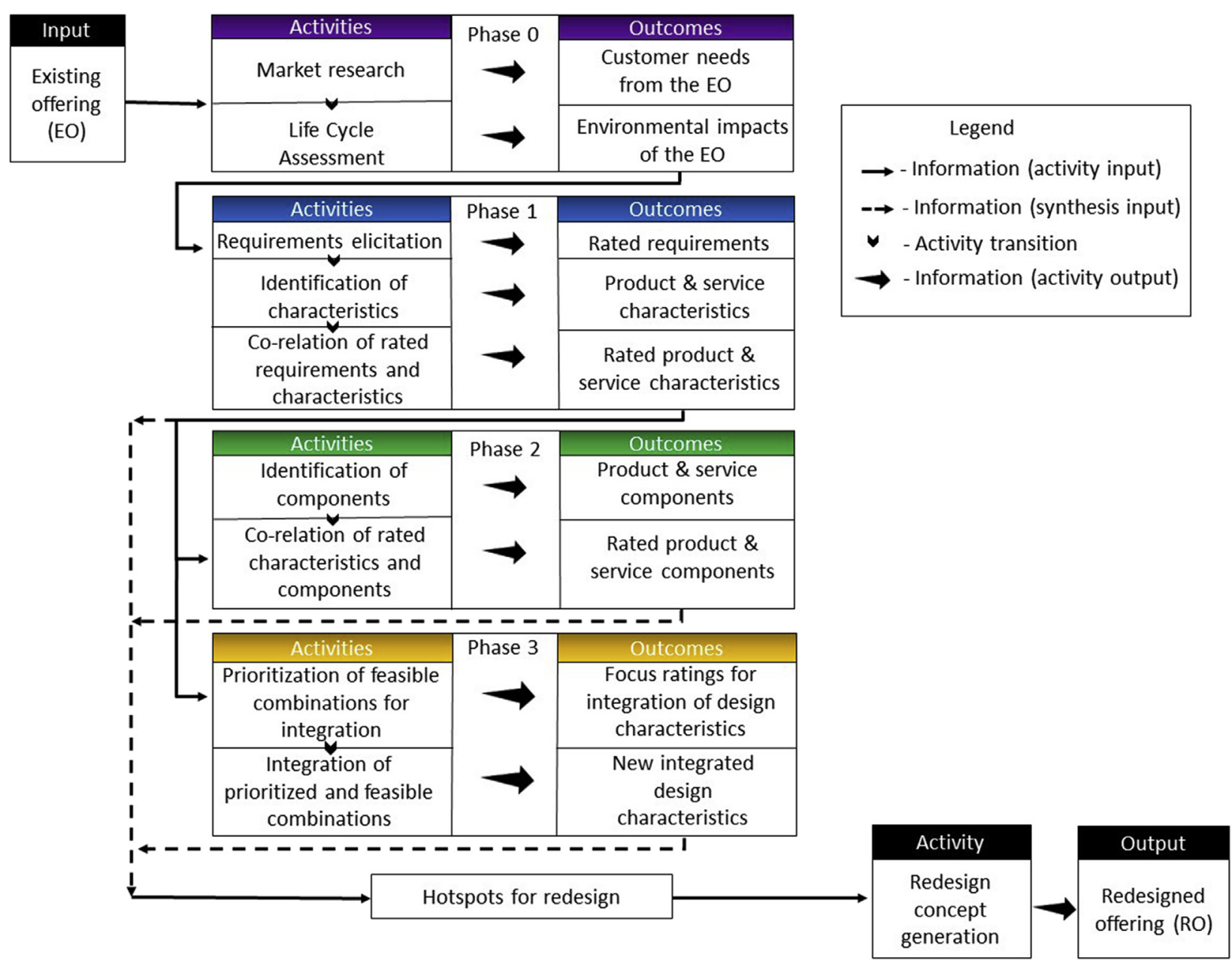

Fig. 1. Overview of lifecycle-oriented function deployment (LFD).

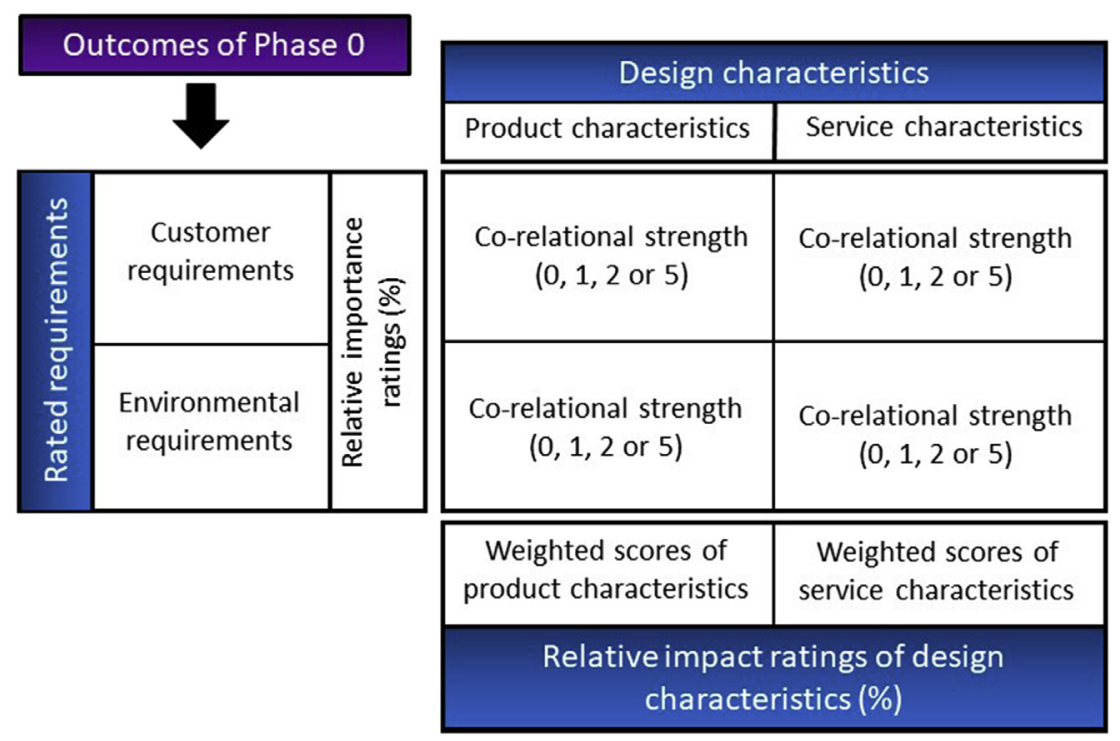

Fig. 2. Skeletal representation of the Phase 1 matrix and respective outcomes. 


\subsubsection{Activity 1.1. Requirements elicitation}

This activity is carried out in three sub-activities. Design requirements in this research refers to certain aspects of the offering that need to be addressed during its redesign, from the perspective of customers and the environment. In the first sub-activity, the raw data regarding customer needs obtained from Activity 0.1. is translated into design requirements. Subsequently, importance ratings of these requirements are established by the participants of the workshop, based on the market research (see Section 3.2.1) and on their expert knowledge regarding the EO (see Akao, 1990; Ulrich and Eppinger, 2012), on a numerical scale between 0 and 5 (0 - not important at all; 5 - most important). It is sensible for the minimum of the scale to be 0 due to two reasons: the first is to maintain consistency with the importance ratings for the category of environmental requirements (to be explained later), while the second is, in case of a group decision, to allow a perception of "not important at all" to be expressed. The numerical ratings of the different requirements are thereafter translated into relative importance ratings of customer requirements $\left(R_{C_{i}}\right)$ using the formula

$$
R_{C_{i}}=\frac{C_{i}}{\sum_{i=1}^{n} C_{i}}
$$

where $C_{i}$ is a numerical scale rating between 0 and 5 for each customer requirement, $\mathrm{i}=1,2,3 \ldots \mathrm{n}$, and $\mathrm{n}$ is the number of customer requirements.

In the second sub-activity, environmental requirements and their relative importance are derived by carrying out the following three-step procedure. The input is the results from the LCA study of the EO (see Section 3.2.2). LCA results are commonly expressed as impact scores at the midpoint level. Current recommendations on LCA methodology (Hauschild et al., 2013) suggest the use of eleven such mid-point impact categories, ${ }^{4}$ even if, in practice, fewer are often used. LCA results in such a format can be difficult to relate to by non-specialists, such as designers. Further, the results for several impact categories are often correlated, as not all of them necessarily carry meaningful information individually. For instance, a study by Janssen et al. (2017) based on 18 different LCA studies showed that the impact category non-renewable energy use (NREU) strongly correlated with global warming potential (GWP), while renewable energy use (REU) strongly correlated with eutrophication potential (EP), acidification potential (AP) and photochemical oxidant creation potential (POCP), but did not correlate with GWP and NREU. In addition, EP strongly correlated with AP. There were exceptions from these observations, however, such as for LCA studies of specific technologies or products.

For these reasons, it is suggested to simplify LCA results in the first step by filtering and choosing only a few relevant impact categories as environmental requirements, by weighting all the scores of all the impact categories to a single score. Only those impact categories that contribute the most to the weighted single score are selected. Furthermore, impact categories with strong correlations can be deselected. It is recommended to use multiple weighting methods for weighting to a single score, as different methods are built on different principles for valuing the environment and thus put different weights to different environmental impact categories. For example, the EPS method (Steen, 1999) is based on a willingness to pay, whereas the ReCiPe (Goedkoop et al., 2009) weighting factors derive from the judgment of an expert panel. An additional principle is the distance to politically set targets, operationalised, for example, in the EDIP method (Hauschild and Potting, 2015). For

\footnotetext{
${ }^{4}$ Midpoint impact categories are referred to as impact categories from here on.
}

each weighting method used, the outcome is a set of weighted scores for the midpoint impact categories. In practice, to obtain the weight of the different impact categories, the physical flows quantified as a result of the inventory phase of LCA are multiplied with the midpoint characterization factor. It is converted to a nondimensional figure through normalization and expressed in common units across the different impact categories through multiplication with the weighting factors, as described in Itsubo (2015) and the formula

$W I=\sum_{\text {Impact }} \sum_{X}\left(\frac{\operatorname{In} v(X) * C F^{\text {Impact }}(X)}{N V^{\text {Impact }}} * W F_{2}^{\text {Impact }}\right)$,

where WI indicates the weighted impact, $\operatorname{In} v(X)$ is the inventory results for substance $\mathrm{X}, C F^{\text {Impact }}(X)$ is the midpoint characterization factor of substance $X$ in a particular impact category (impact), $N V^{\text {Impact }}$ is the normalization reference for the impact category (impact), and $W F_{2}^{\text {Impact }}$ is the weighting factor of the impact category (impact). For more details, see Itsubo (2015).

The first step in the second sub-activity starts with normalising the weighted impacts (WI from [2]) internally for each weighting method, that is, their relative contribution to the single score is calculated and expressed as a percentage using the formula

$w_{k j}=\frac{W I_{j}}{\sum_{j=1}^{g} W I_{j}},\left(0 \leq w_{k j} \leq 1\right)$

where $w_{k j}$ represents the weighted normalised impact score for impact category $j$ based on weighting method $k$ expressed as a percentage contribution to the overall single score. Also, $\mathrm{j}=1,2,3 \ldots$ $\mathrm{g}$; here, $\mathrm{g}$ is the number of impact categories considered in the weighting method $k$.

For each weighting method, those impact categories with the highest contribution to the single score are selected. Often, for each weighting method, there are a few impact categories (i.e., one to four) that dominate the contribution to the single score. Should this not be the case, the impact categories that individually contribute to more than $15 \%$ (arbitrary) or that in total contribute to more than $80 \%^{5}$ to the overall score are selected. A total list of all impact categories pointed to as significant by all the applied weighting methods is then constructed. Typically, there will be several methods that point to the same impact category as significant (e.g., GWP), whereas other impact categories may be pointed to by only one weighting method. In such cases, further investigation (beyond the specific weighting method) of the impact category is required to see what resources, substances, or emissions contribute to the impact category. This is needed to identify equivalent impact categories across different weighting methods. The list can be further simplified if the impact categories that are correlated are deselected. Such deselection is then based on a detailed analysis of the LCA study of the EO and requires some LCA expertise, but such deselection is not always necessary. Examples of LCA studies where a similar method for interpreting LCA results have been applied include Tillman et al. (1998), Willskytt and Tillman (2019) and Böckin and Tillman (2019). When the most important impact categories have been identified, dominance analysis should be carried out. That entails investigating which processes and aspects of the offering along the lifecycle contribute the most to the selected impact categories. Doing so will support the designer's work of

\footnotetext{
${ }^{5}$ A similar approach is suggested by the European Commission, PEFCR Guidance document - Guidance for the development of Product Environmental Footprint Category Rules (PEFCRs), version 6.3, December 2017.
} 
where to focus the redesign effort.

The second step is to aggregate and create an average of the weighted normalised impact scores of the selected environmental impact categories over the different weighting methods (from [3]), using the formula

$E_{j}=\frac{\sum_{k=1}^{h} w_{k j}}{h}, 0 \leq E_{j} \leq 1$

where $E_{j}$ is the aggregated weighted impact score for impact category $\mathrm{j}, k=1,2 \ldots, h$, and $h$ is the number of weighting methods. Thereafter, the third step is to normalize the aggregated weighted impact score of the selected impact category $\mathrm{j}$ to derive relative ratings of environmental requirements $\left(R_{e_{j}}\right)$. To do so, the formula

$R_{e_{j}}=\frac{E_{j}}{\sum_{j=1}^{p} E_{j}}$

is used, where $j=1,2,3, \ldots p$ and $p$ is the number of selected impact categories. This step is prescribed in order to relatively prioritize the selected impact categories and, thus, to derive relatively prioritized ratings of requirements from the environmental point of view.

In the third sub-activity, the importance of the customer requirements in relation to the environmental requirements is decided. This is done by the designers by carrying out the factorization

$\left(R_{C_{i}}\right) * \mathrm{f},\left(R_{e_{j}}\right) *(1-\mathrm{f}),(0 \leq f \leq 1)$,

where $f$ is a relative factor of importance for the category of customer requirements over that of environmental requirements assigned by the designer. This step is introduced to be able to relatively prioritize the customer and environmental categories of the requirements. This relative prioritization is necessary to provide the control to the designers to set the relative importance of environmental and customer requirements (based upon the design strategies of the manufacturer) and prevent any in-built bias on the weighting (bias originating from the disproportionate number of requirements between the two categories of requirements).

\subsubsection{Activity 1.2. Derivation of design characteristics (product and} service)

Design characteristics of the EO are derived by the designers participating in the workshop, either based on their tacit knowledge or with documented information. A design characteristic in this research is defined as a measurable feature belonging to specific design objects that can be influenced by the designers to achieve desired outcomes, in line with Arai and Shimomura (2005). These characteristics can be expressed with different levels of granularity, depending on the maturity of the design object. In the case of the redesign of product-centric offerings with complementary services, the product design objects are usually well defined and relatively mature. Thus, the designers can directly derive the product design characteristics by analysing the design object. If the service design characteristics of the same offering are relatively immature, designers can refer to the generic list presented in Table 1 for guidance on how to derive the characteristics.

The list can be utilized as a guiding tool while deriving the final service design characteristics for an existing (immature) service design object of the EO. It is a synthesis result of a rigorous review of the literature that has described the service characteristics of various industrial service offerings (see Appendix A for details). The descriptions of measurables are partly derived from the stated literature and partly based on the authors' own reasoning. Environmental impacts of the service offering being designed or redesigned can be influenced by manipulating the identified service design characteristics: e.g., if a service offering is too responsive, it might have higher environmental impacts, due to an increase in the frequency of transportation of the involved service actors. The final list does not have to be limited to the characteristics presented in Table 1 but can also be additionally derived based on the customer/ environmental requirements following the procedure prescribed by Akao (1990).

\subsubsection{Activity 1.3. Co-relation of PSS characteristics and requirements}

The rated requirements (see Activity 1.1) are co-related with the identified design characteristics (see Activity 1.2 ) by the designers in the same way as in traditional QFD (see Akao, 1990). The difference in this activity from the traditional QFD is in the analysis of both product and service design characteristics. Based on the knowledge derived from market research and dominance analysis of LCA by the respective experts, normalised relative impact ratings of both product and service design characteristics on the rated design requirements are obtained as a result of this activity.

\subsection{Phase 2 -Prioritization of design components}

This phase is carried out with a QFD-based matrix (see Akao, 1990) on another spreadsheet, in two sequential activities: Activity 2.1. Identification of product and service components and Activity 2.2. Co-relation of the rated characteristics and identified components. The skeletal representation of the matrix is illustrated in Fig. 3.

\subsubsection{Activity 2.1. Derivation of product and service design components}

Initially, the participants of the workshop identify the major product and service components of the EO. In this research, design components are defined as specific structures of the entire product or service offering that are designed to fulfil the design requirements, in line with Arai and Shimomura (2005). The components of services are classified into human resources, information, and service tools (Sakao et al., 2017). Human resources include personnel involved in carrying out the service activities such as service technicians and on-line support staff. Information regarding the service activities can include, for example, service manuals and information regarding product use history. The service tools can include both hard and soft tools, for example, repair tools and analysis software (ibid). When the service design objects during redesign are relatively immature or non-existent, the service components can be described with a relatively lower level of granularity.

\subsubsection{Activity 2.2. Co-relation of product and service components} with the characteristics

The outcome of Activity 1.3. of Phase 1 (i.e., rated product and service characteristics) is used as an input to this matrix (see Fig. 3). This activity is carried out in the same way as in traditional QFD (see Akao, 1990). The difference in this activity from traditional QFD is in the analysis of both product and service design components.

\subsection{Phase 3 - Systemic integration of design characteristics}

As discussed in Section 2, the integration of product and service aspects from a systems and lifecycle perspective is the essence of PSS design in general. Derivation of integrated product and service characteristics partly based on their exchangeability, which can meet the requirements and can enhance the said value, is crucial in 
Table 1

Service design characteristics and measurables.

\begin{tabular}{|c|c|c|}
\hline $\begin{array}{l}\text { Service design } \\
\text { characteristics }\end{array}$ & Description of measurables & References \\
\hline Responsiveness & Time taken to deliver a service/response to the customer. & $\begin{array}{l}\text { Borgianni and Rotini (2015); Doultsinou et al. (2009); Easton and } \\
\text { Pullman (2001); Lam et al. (2015); Vidor et al. (2015); Wang et al. } \\
\text { (2017); Zheng and Pulli (2007) }\end{array}$ \\
\hline Labour intensity & $\begin{array}{l}\text { Level of involvement of human resource in a service activity. Measured in } \\
\text { terms of the number of personnel involved in the activity and the effort } \\
\text { spent by the personnel. }\end{array}$ & Smith et al. (2014); Wang et al. (2017) \\
\hline Customizability & $\begin{array}{l}\text { Ability to provide a customer the options to personalize the offering based } \\
\text { on their needs. Measured in terms of quantity and type of information } \\
\text { collected from customers (input) and corresponding choices given to } \\
\text { personalize the offering (output). }\end{array}$ & $\begin{array}{l}\text { Doultsinou et al. (2009); Gliatis and Minis (2007); Lam et al. (2015); } \\
\text { Smith et al. (2014); Vidor et al. (2015); Wang et al. (2017); Zheng and } \\
\text { Pulli (2007) }\end{array}$ \\
\hline Affordability & Level of pricing for a service activity in monetary terms. & $\begin{array}{l}\text { Borgianni and Rotini (2015); Doultsinou et al. (2009); Song et al. (2014); } \\
\text { Vidor et al. (2015); Zheng and Pulli (2007) }\end{array}$ \\
\hline Security & $\begin{array}{l}\text { Level of protection of the customer data/information. Measured in terms of } \\
\text { security of user information, security while using service, transparency, } \\
\text { confidentiality, etc. }\end{array}$ & Borgianni and Rotini (2015); Doultsinou et al. (2009); Lam et al. (2015) \\
\hline Reliability & $\begin{array}{l}\text { Level of dependability of fulfilment of the intended functions of a service } \\
\text { activity. Measured in terms of consistency of accurate results of service } \\
\text { activities. }\end{array}$ & Doultsinou et al. (2009); Easton and Pullman (2001); Lam et al. (2015) \\
\hline Modularity & $\begin{array}{l}\text { Level to which offerings can be separated and recombined based on } \\
\text { customer needs. Measured in terms of the absolute number of potential } \\
\text { modular alternatives of offerings. }\end{array}$ & Doultsinou et al. (2009); Vidor et al. (2015) \\
\hline
\end{tabular}

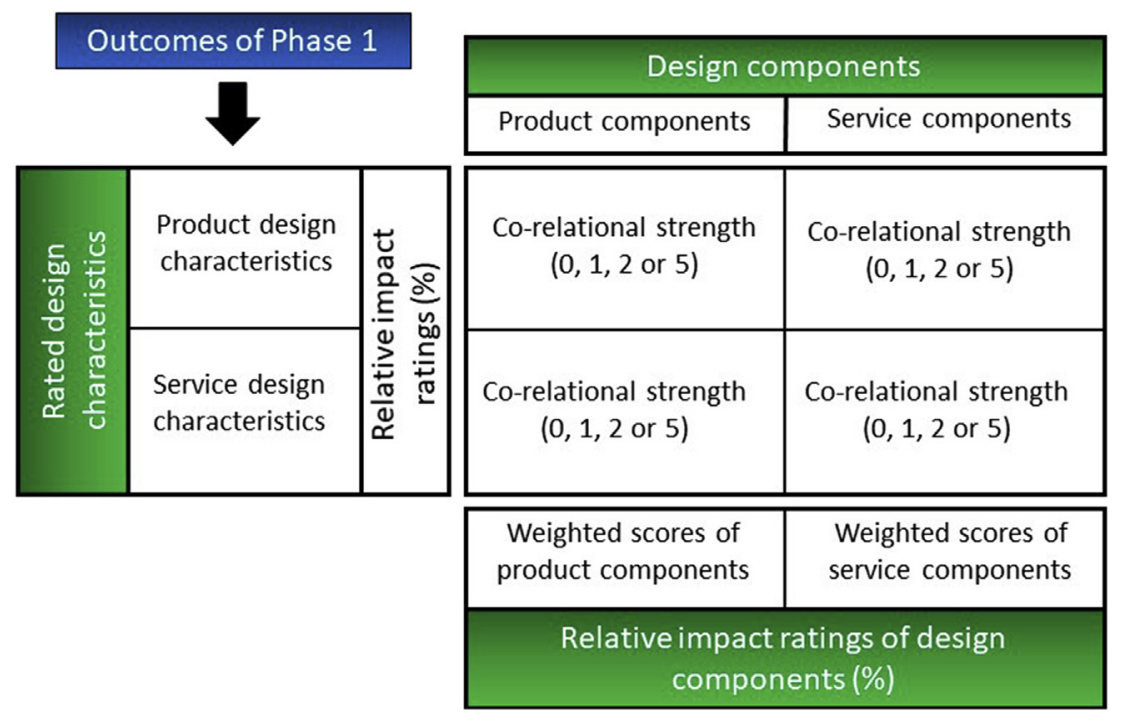

Fig. 3. Skeletal representation of the Phase 2 matrix and its respective outcomes.

this context. However, this serves as a decision-making challenge as the designers need to select specific combinations of product and service characteristics for effective integration, out of a large number of potential alternatives, which increases in a combinatorial manner with the numbers of product and service characteristics. This phase addresses this challenge by supporting designers to make effective decisions regarding the integration of feasible and highly rated product and service design characteristics, by building upon the outcome of Activity 1.3. It is carried out in two sequential activities: Activity 3.1: Prioritization of feasible combinations for integration and Activity 3.2: Integration of feasible combinations.

\subsubsection{Activity 3.1. Prioritization of feasible combinations for integration}

Initially, the participants of the workshop are prescribed to assign an exchangeability factor (E-factor) for each individual product and service design characteristic in binary value (1 or 0 ). The E-factor is defined as a factor that indicates whether a product or service design characteristic displays the possibility to exchange its design efforts with service or product, respectively (for the definition of "exchangeability", see Sakao and Lindahl, 2015). The potential combinations are identified and prioritized using the formula

$z_{a, b}=\left(x_{a}+y_{b}\right) *\left(E_{a} * E_{b}\right)$,

where $\mathrm{a}=1,2, \ldots \mathrm{d}$; $\mathrm{d}$ is the total number of product design characteristics; $\mathrm{b}=1,2, \ldots \mathrm{e} ; \mathrm{e}$ is the total number of service design characteristics; $x_{a}$ and $y_{b}$ represent the normalised relative impact ratings for product and service design characteristics $a$ and $b$, respectively (outcome of Activity 1.3 ); $E_{a}$ and $E_{b}$ represent the exchangeability factors for product and service design characteristics $a$ and $b$, respectively; and $z_{a, b}$ is the focus ratings for integration (FRI) for combinations of product and service design characteristics $a$ and $b$, respectively.

Rate of prioritization for the integration is determined by the aggregation of relative importance ratings of the product and 
service design characteristic (see Activity 1.3). Ra of feasibility for integration is determined by considering the exchangeability of the respective product and service design characteristic. The combinations with the highest FRI (as an outcome of formula [7]) are selected for further analysis. The high degree of focus does not suggest that the represented design characteristics must be integrated but rather that they should be prioritized for attempting potential integration by the designers. This narrows down the number of alternatives for the potential integration of design characteristics, which thereafter can support in the generation of integrated PSS functions that can effectively influence the design requirements.

\subsubsection{Activity 3.2. Integration of feasible combinations}

The designers further investigate if the integration of the selected combinations is sensible and feasible, qualitatively. If deemed sensible and feasible, they are earmarked to be integrated in the concept generation phase, with the introduction of relevant design changes. It is important to note that all highly rated product and service design characteristics may not necessarily make sense nor be feasible for integration.

\section{Assessment of the design navigator through a case study}

\subsection{Research design}

The development and assessment of the LFD were carried out through a case study, based on the action design research (ADR) (Sein et al., 2011) method primarily used in the discipline of information science. ADR is originally defined by Sein et al. (2011) as "a research method for generating prescriptive design knowledge through building and evaluating IT artifacts in an organizational setting". In this study, the principles of the ADR method were used as an inspiration to generate prescriptive design knowledge (in terms of the navigator LFD) to support the design and evaluation of concepts of environmentally benign PSSs, in a case study within an organizational setting (see Appendix B for more details). The research techniques used include the retrospective technique of document analysis (Bowen, 2009), a conceptual design workshop with a focus group setting (Stewart and Shamdasani, 1990) and a semi-structured interview with the personnel of the case company (Leech, 2002).

\subsection{Description of the case company and existing offering}

The case study was carried out with a multinational pulp and paper company, which, among other things, manufactures incontinence products. An incontinence product offering was chosen as it has substantial environmental impacts and is a relatively simple product. It also has service functions that indicate integration possibility, thus promoting a better understanding of the method application.

The users of incontinence products are adults, often elderly, having varying degrees of incontinence problems, from trouble preventing the leakage of urine during stressful activities, to the complete inability to control bladder and/or bowel. This study focuses on the use of such products by residents of elderly homes in Sweden, who are the main users of the EO. The main customer of the offering is seen as a typical Swedish elderly home and its staff, who will be referred to as nurses from here on. The EO under focus in this research includes a portfolio of incontinence products (e.g., products with different sizes, materials, or components) and complementary service activities (e.g., information provision regarding the suitability of specific products for specific users) (see Appendix C for more details).

\subsection{Results of phase 0}

\subsubsection{Activity 0.1: Customer/market survey}

The information for this activity was obtained through a retrospective analysis of a report provided by the case company. This report contains the details and results of a qualitative study of the users of the EO done in January 2008 by the case company using a face-to-face interview technique. In this study, a total of eight interviews were carried out by the case company, each of which lasted approximately $45-60 \mathrm{~min}$. The participants of the study were reported to be the main users of the EO, all female, with five of them between the age of 50-80 years old and three between the age of 20-50 years old. Functionality (i.e., retaining fluids) was stated as a primary need for both types of users. The younger users primarily wanted the offering to be discrete and aesthetic. The older users primarily wanted the offering to be comfortable. Further details of this document are not disclosed here due to confidentiality related issues. $^{6}$

\subsubsection{Activity 0.2: LCA of the EO}

The results of the LCA for the EO were also taken from a previous study of the EO by Willskytt and Tillman (2019). In the study, a ward at an elderly home was investigated regarding environmental impacts associated with the types of products the elderly used from the product portfolio. Seven users (elderly residents) lived at the studied ward and used a variation of the product types presented in Appendix C, both in terms of product size, product type and absorption capacity. The selection of what products to use for each user had been made by the nurses, based on their experience. For more details about the EO, see Willskytt and Tillman (2019).

In this LCA study, the functional unit was the "provision of incontinence-related hygiene functions for 1 week at a studied ward in an elderly home". Two different weighting methods, EPS (Steen, 1999) and ReCiPe version 2008 (Goedkoop et al., 2009), were used to determine the dominating environmental impact categories of the EO. Formula [2] was applied to calculate the impacts, using the weighting methods. Using ReCiPe, agricultural land occupation (46\%), followed by global warming potential (GWP) (21\%) and fossil resource depletion (FRD) (18\%), dominated the result. The EPS results, however, showed that use of abiotic stock resources (63\%), which can be co-related to FRD, together with emissions to air (35\%, mainly $\mathrm{CO}_{2}$ emissions), that is, GWP, dominated the overall impacts. The contribution from land use was merely $0.15 \%$. Based on the combined results from EPS and ReCiPe, land use, FRD and GWP dominated the environmental impact over the lifecycle of the EO (formula [3] was applied). The dominance analysis of the impact assessment result showed that the production of superabsorbent polymer material (SAP) and other fossilbased nonwoven materials contributed largely to FRD and associated GWP, while production of fluff (wood-based) material contributed the most to use of land.

\subsection{Results of phase 1}

A focus group-based conceptual design workshop was carried out at the case company. Participants of the workshop included the authors of this research, one product developer, one business

\footnotetext{
6 The qualitative study reported in this document was not carried out by the authors of this article. It was carried out and documented entirely by the case company with the users of their EO to gather insights into the user needs. The authors received and analyzed relevant parts of this document to extract the customer needs of the EO. Personal details of the participants of this study were anonymized in the document.
} 
Table 2

Normalised importance ratings of customer requirements.

\begin{tabular}{ll}
\hline Customer requirements & Normalised importance rating (applying formula [1]) \\
\hline Leakage prevention & 0.25 \\
Odour prevention & 0.20 \\
Skin-friendliness & 0.20 \\
Wearing comfort & 0.15 \\
Discreteness & 0.15 \\
User-friendliness & 0.05
\end{tabular}

Table 3

Normalised and relativised importance ratings of environmental requirements.

\begin{tabular}{lll}
\hline $\begin{array}{l}\text { Environmental } \\
\text { requirements }\end{array}$ & $\begin{array}{l}\text { Aggregated impact score } \\
\text { (applying formula [4]) }\end{array}$ & $\begin{array}{l}\text { Normalised and relativised } \\
\text { importance rating (applying } \\
\text { formula [5]) }\end{array}$ \\
\hline $\begin{array}{c}\text { Decrease GWP } \\
\text { per function }\end{array}$ & 0.28 & 0.30 \\
$\begin{array}{c}\text { Decrease FRD } \\
\text { per function }\end{array}$ & 0.41 & 0.44 \\
$\begin{array}{c}\text { Decrease land } \\
\text { use per } \\
\text { function }\end{array}$ & 0.24 & 0.26 \\
\hline
\end{tabular}

Note: The mathematical demonstration of the application of formula [4] for the environmental requirement (impact category) 'decrease GWP per function' is given as an example: $[(0.35+0.21) / 2=0.28] .0 .35$ is the relative importance of the impact category from the EPS method, and 0.21 represents the relative importance of the same impact category from the ReCiPe method.

developer (with service-related experience) and one environmental expert of the company. The workshop lasted for around $5 \mathrm{~h}$, during which the procedure described in Section 2 was followed.

\subsubsection{Activity 1.1: Requirements elicitation}

Documented information regarding customer needs and respective importance provided by the case company (see Section 4.3.1) was used as the outcome of market research. This information was analyzed and translated into draft design requirements by the authors prior to the workshop. These requirements were further refined and contextualized during the workshop, and the corresponding importance given by the users for the needs was translated onto the numerical scale of $0-5$ importance ratings (see Section 3.3.1). The final list of user requirements and respective ratings given on the scale were leakage prevention (concerning leakage of fluids) -5 , odour prevention (concerning bad odour) 4 , skin-friendliness (concerning irritation for the user's skin) -4 , wearing comfort (concerning discomfort to user) -3 , discreteness (concerning notice-ability to others and information regarding user's secureness) -3 , and user-friendliness (concerning the easiness to use) -1 . The normalised importance ratings of the customer requirements are calculated by applying formula [1] and are detailed in Table 2.

In the second step, results from the LCA of the EO carried out in Activity 0.2 (see Section 4.3.2) were used to elicit rated environmental requirements by applying the generic procedure described in Section 3.3.1. The yielded environmental requirements and the calculation of their respective normalised ratings are presented in Table 3.

In the third step, the designers assigned the relative importance factor $\mathrm{f}=0.5$ (weighting environmental and customer requirements equally important), and formula [6] was applied to the results obtained from the above Tables 2 and 3, to obtain normalised relative importance ratings for both customer and environmental requirements presented in Table 4.

\subsubsection{Activity 1.2: Derivation of product and service characteristics}

Prior to the workshop, based on the authors' understanding of the product-based offering and in reference to the list of service design characteristics (see Table 1), lists of product and service design characteristics that are relevant for the EO were derived. These lists were further refined and added to, in the workshop after consultation with the participants. A total of nine product design characteristics and a list of seven service design characteristics were finalized and are presented in Appendix D (see Tables D1 and D2).

\subsubsection{Activity 1.3: Co-relation of identified characteristics and rated requirements}

The identified design characteristics and rated requirements (obtained from Activity 1.1 and 1.2) were co-related. This corelation was made mainly by the participants of the workshop using a QFD-based matrix on a spreadsheet based on their extant knowledge regarding the EO and the results from dominance analysis carried out in the LCA. The result of this co-relation is shown in Fig. 4. The result indicates that the type of material and customizability are two of the highest-rated product and service design characteristics, sharing $14 \%$ and $13 \%$ of the total relative impact ratings, respectively.

\subsection{Results of phase 2}

\subsubsection{Activity 2.1: Derivation of product and service components}

Initially, the authors had identified the technical product and service components based on their knowledge of the EO. These were later refined and confirmed by the participants of the workshop. The final list of product components included the following three: 1) absorption pad (component responsible for absorbing fluids), 2) fastener (component responsible for affixing the pad onto the user's body, i.e., fixation pants for Inco 3 and 4), and 3) auxiliary parts (additional component that can increase the fluid retention capacity of the product). The final list of service components included the following: 1) support staff (human resource to carry out service activities, i.e., consultation), 2) information (provision or collection of information, i.e., regarding size, fit, etc.) and 3) support tools (computer-aided support, databases, handbooks, etc.).

\subsubsection{Activity 2.2: Co-relation of product and service components} with the rated characteristics

In this activity, the identified components were co-related with the rated design characteristics (the outcome of Activity 1.3). The spreadsheet of the QFD-based matrix used for this phase is given in Fig. 5. The co-relation was initially done by the authors and was then refined and confirmed by the participants of the workshop. The results illustrated in the figure indicate that the absorption pad and information of the offering are two of the highest-rated product and service components, sharing $24 \%$ and $19 \%$ of the total relative impact ratings, respectively.

\subsection{Results of phase 3}

This phase involved the identification and potential integration of hotspots of feasible combinations of product and service design characteristics. It was carried out in two activities (see Section 3.5) in the workshop and is described as follows. Results from the spreadsheet of the matrix of this phase, initially filled out by the authors and then confirmed by the participants of the workshop, are presented in Fig. 6.

\subsubsection{Activity 3.1: Prioritization of feasible combinations for integration}

Initially, E-factors for product and service design characteristics were assigned by the authors based on their knowledge of EO (see Fig. 6). All of the product design characteristics were given an E- 
Table 4

Normalised and relativised customer and environmental requirements.

\begin{tabular}{ll}
\hline Design requirements & Normalised relative importance ratings (applying formula [6]) \\
\hline Customer requirements & 0.12 \\
Leakage prevention & 0.10 \\
Odour prevention & 0.10 \\
Skin-friendliness & 0.07 \\
Wearing comfort & 0.07 \\
Discreteness & 0.02 \\
User-friendliness & \\
Environmental requirements & 0.15 \\
Decrease GWP per function & 0.22 \\
Decrease FRD per function & 0.13 \\
Decrease land use per function & \\
\hline
\end{tabular}

\begin{tabular}{|c|c|c|c|c|c|c|c|c|c|c|c|c|c|c|c|c|c|c|c|}
\hline \multirow{2}{*}{\multicolumn{2}{|c|}{ Requirements for the offering }} & \multirow[b]{2}{*}{$\begin{array}{l}\text { Normalized } \\
\text { relative } \\
\text { importance } \\
\text { rating }\end{array}$} & \multirow[b]{2}{*}{$\begin{array}{l}\text { Normalized } \\
\text { relative } \\
\text { importance } \\
\text { rating in \% }\end{array}$} & \multicolumn{9}{|c|}{ Product characteristics } & \multicolumn{7}{|c|}{ Service characteristics } \\
\hline & & & & 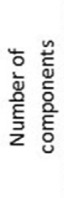 & 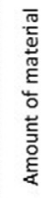 & 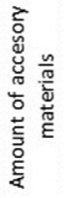 & 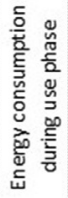 & 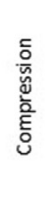 & 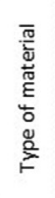 & 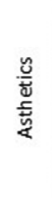 & $\stackrel{\tilde{\omega}}{\tilde{\Sigma}}$ & 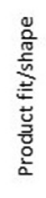 & 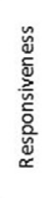 & 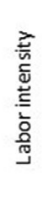 & 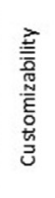 & 竎 & 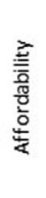 & 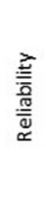 & 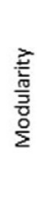 \\
\hline \multirow{6}{*}{ ๕ } & Leakage prevention & 0.12 & $12 \%$ & 5 & 5 & 0 & 0 & 2 & 5 & 0 & 1 & 5 & 2 & 5 & 5 & 2 & 1 & 2 & 5 \\
\hline & Odor protection & 0.1 & $10 \%$ & 5 & 2 & 0 & 0 & 0 & 5 & 0 & 0 & 0 & 2 & 5 & 5 & 2 & 1 & 2 & 5 \\
\hline & Skin friendliness & 0.1 & $10 \%$ & 0 & 0 & 0 & 0 & 5 & 5 & 0 & 5 & 5 & 2 & 5 & 5 & 2 & 1 & 2 & 2 \\
\hline & Wearing comfort & 0.07 & $7 \%$ & 2 & 2 & 0 & 0 & 5 & 5 & 1 & 2 & 5 & 0 & 1 & 2 & 0 & 0 & 1 & 1 \\
\hline & Discrete & 0.07 & $7 \%$ & 2 & 5 & 0 & 0 & 1 & 5 & 5 & 0 & 5 & 0 & 0 & 0 & 0 & 0 & 0 & 0 \\
\hline & User friendliness & 0.02 & $2 \%$ & 1 & 0 & 0 & 0 & 1 & 2 & 1 & 0 & 5 & 0 & 1 & 2 & 0 & 0 & 1 & 1 \\
\hline \multirow{3}{*}{$\cong$} & Decrease GWP per function & 0.15 & $15 \%$ & 5 & 5 & 1 & 1 & 1 & 5 & 0 & 5 & 1 & 2 & 0 & 5 & 0 & 2 & 2 & 2 \\
\hline & Decrease FRD per function & 0.22 & $22 \%$ & 5 & 5 & 1 & 1 & 1 & 5 & 0 & 5 & 1 & 2 & 0 & 5 & 0 & 2 & 2 & 2 \\
\hline & Decrease land use per function & 0.13 & $13 \%$ & 1 & 5 & 0 & 1 & 0 & 5 & 0 & 1 & 0 & 2 & 0 & 5 & 0 & 2 & 2 & 2 \\
\hline \multirow{2}{*}{\multicolumn{3}{|c|}{$\begin{array}{c}\text { Legend } \\
\text { CR - Customer requirements } \\
\text { ER - Environmental requirements }\end{array}$}} & Scores & 3.4 & 3.8 & 0.4 & 0.5 & 1.6 & 4.8 & 0.4 & 2.7 & 2.3 & 1.6 & 1.7 & 4.3 & 0.6 & 1.3 & 1.7 & 2.4 \\
\hline & & & $\begin{array}{l}\text { Normalized } \\
\text { impact rating } \\
\text { in } \%\end{array}$ & $10 \%$ & $11 \%$ & $1 \%$ & $1 \%$ & $5 \%$ & $14 \%$ & $1 \%$ & $8 \%$ & $7 \%$ & $5 \%$ & $5 \%$ & $13 \%$ & $2 \%$ & $4 \%$ & $5 \%$ & $7 \%$ \\
\hline
\end{tabular}

Fig. 4. Screenshot of spreadsheet used for Phase 1.

\begin{tabular}{|c|c|c|c|c|c|c|c|c|}
\hline \multirow{2}{*}{\multicolumn{2}{|c|}{ Characteristics of the offering }} & \multirow{2}{*}{$\begin{array}{l}\text { Nomalized } \\
\text { impact in \% }\end{array}$} & \multicolumn{3}{|c|}{ Product components } & \multicolumn{3}{|c|}{ Service Components } \\
\hline & & & Absorption pad & Fastener & Auxiliary parts & Support staff & $\begin{array}{c}\text { Information of the } \\
\text { offering }\end{array}$ & Support tools \\
\hline \multirow{9}{*}{ 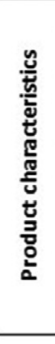 } & Number of components & $10 \%$ & 5 & 5 & 5 & 0 & 1 & 0 \\
\hline & Amount of material & $11 \%$ & 5 & 2 & 2 & 0 & 0 & 0 \\
\hline & Amount of accesory materials & $1 \%$ & 0 & 0 & 5 & 0 & 0 & 0 \\
\hline & Energy consumption during use phase & $1 \%$ & 0 & 0 & 0 & 0 & 0 & 0 \\
\hline & Compression & $5 \%$ & 5 & 1 & 1 & 0 & 1 & 0 \\
\hline & Type of material & $14 \%$ & 5 & 5 & 5 & 0 & 2 & 0 \\
\hline & Asthetics & $1 \%$ & 2 & 2 & 5 & 0 & 1 & 0 \\
\hline & Dryness & $8 \%$ & 5 & 0 & 5 & 0 & 1 & 0 \\
\hline & Product fit/shape & $7 \%$ & 2 & 5 & 2 & 5 & 5 & 2 \\
\hline \multirow{7}{*}{ 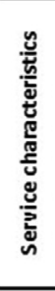 } & Responsiveness & $5 \%$ & 0 & 0 & 0 & 5 & 5 & 1 \\
\hline & Labor intensity & $5 \%$ & 0 & 0 & 0 & 5 & 2 & 1 \\
\hline & Customizability & $13 \%$ & 2 & 2 & 1 & 5 & 5 & 2 \\
\hline & Security & $2 \%$ & 0 & 0 & 0 & 2 & 5 & 0 \\
\hline & Affordability & $4 \%$ & 0 & 0 & 0 & 0 & 0 & 0 \\
\hline & Reliability & $5 \%$ & 2 & 1 & 0 & 2 & 5 & 2 \\
\hline & \multirow[t]{3}{*}{ Modularity } & $7 \%$ & 0 & 0 & 0 & 2 & 1 & 1 \\
\hline & & Impact in \% & $295 \%$ & $217 \%$ & $229 \%$ & $176 \%$ & $227 \%$ & $66 \%$ \\
\hline & & $\begin{array}{l}\text { Nomalized } \\
\text { impact in \% } \\
\end{array}$ & $24 \%$ & $18 \%$ & $19 \%$ & $15 \%$ & $19 \%$ & $5 \%$ \\
\hline
\end{tabular}

Fig. 5. Screenshot of spreadsheet used for Phase 2. 
factor value of 1 , as it was deemed that design effort for each product characteristic could potentially be replaced with that of a service characteristic in meeting the requirements (e.g., type of material can be influenced by customizability of service activity in measuring the user's size). Service design characteristics responsiveness, security and affordability were deemed not to have any exchangeability in relation to the product design characteristics, and thus were given 0 E-factor value (i.e., security of user information does not have any influence on any product design characteristics). Formula [7] was then applied to get the FRI for the various combinations. The results are presented in the intersecting cells of the respective product design characteristics (in rows) and service design characteristics (in columns) in Fig. 6. The combinations with $0 \%$ FRI are highlighted by grey coloured cells, and the combinations with high FRI (the arbitrary cut-off rating is chosen as $20 \%$ ) are highlighted by red coloured cells. In this case, out of a potential sixty-three combinations of product and service design characteristics, the top six combinations are identified and selected for further analysis (see Fig. 6). These were later reviewed and confirmed to be accurate by the workshop participants.

\subsubsection{Activity 3.2: Integration of selected combinations design} characteristics

Six of the top highly rated combinations are selected for further analysis and are presented in Table 5. During the analysis, the feasibility for increasing the integration was investigated qualitatively, initially by the authors and later confirmed by the workshop participants. It was deemed that all the selected combinations had feasibility for integration. This assessment is qualitative: for example, Combination Number 2 was deemed to be feasible, as manipulating the service characteristic customizability by potentially collecting more detailed information regarding user characteristics and needs (i.e., health status) would give the opportunity to manipulate the amount of material of the product offering by picking an appropriate incontinence product with the required amount of material.

\subsection{Illustration and assessment of the utility of the outcomes}

\subsubsection{Illustration of utility of the outcomes in the concept generation phase}

Redesign based on the results of Phases 1 and 2 could be forwarded to the respective designers for further development as the specific redesign of product or service would not influence the design of service or product, respectively (i.e., product or service redesign could be performed within its own boundary). Redesign based on the results of Phase 3, however, needed close collaboration of all the participants of the workshop, as the integration of product and service characteristics to reduce environmental

\begin{tabular}{|c|c|c|c|c|c|c|c|c|c|c|}
\hline \multirow{4}{*}{\multicolumn{2}{|c|}{$\begin{array}{l}\text { Matrix to determine focus } \\
\text { ratings for integration (FRI) }\end{array}$}} & & & \multicolumn{7}{|c|}{ Service characteristics } \\
\hline & & & & Responsiveness & Labor intensity & Customizability & Security & Affordability & Reliability & Modularity \\
\hline & & \multirow[t]{2}{*}{$\begin{array}{l}\text { Exchang eability } \\
\text { factor (E-factor) }\end{array}$} & & 0 & 1 & 1 & 0 & 0 & 1 & 1 \\
\hline & & & $\begin{array}{c}\text { Nomalized } \\
\text { impact rating } \\
\text { in } \%\end{array}$ & $5 \%$ & $5 \%$ & $13 \%$ & $2 \%$ & $4 \%$ & $5 \%$ & $7 \%$ \\
\hline \multirow{9}{*}{ 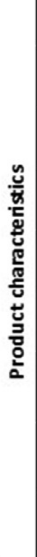 } & Number of components & 1 & $10 \%$ & $0 \%$ & $15 \%$ & $23 \%$ & $0 \%$ & $0 \%$ & $15 \%$ & $17 \%$ \\
\hline & Amount of material & 1 & $11 \%$ & $0 \%$ & $16 \%$ & $24 \%$ & $0 \%$ & $0 \%$ & $16 \%$ & $18 \%$ \\
\hline & $\begin{array}{c}\text { Amount of accesory } \\
\text { materials }\end{array}$ & 1 & $1 \%$ & $0 \%$ & $6 \%$ & $14 \%$ & $0 \%$ & $0 \%$ & $6 \%$ & $8 \%$ \\
\hline & $\begin{array}{c}\text { Energy consum ption during } \\
\text { use phase }\end{array}$ & 1 & $1 \%$ & $0 \%$ & $6 \%$ & $14 \%$ & $0 \%$ & $0 \%$ & $6 \%$ & $8 \%$ \\
\hline & Compression & 1 & $5 \%$ & $0 \%$ & $10 \%$ & $18 \%$ & $0 \%$ & $0 \%$ & $10 \%$ & $12 \%$ \\
\hline & Type of material & 1 & $14 \%$ & $0 \%$ & $19 \%$ & $27 \%$ & $0 \%$ & $0 \%$ & $19 \%$ & $21 \%$ \\
\hline & Asthetics & 1 & $1 \%$ & $0 \%$ & $6 \%$ & $14 \%$ & $0 \%$ & $0 \%$ & $6 \%$ & $8 \%$ \\
\hline & Dryness & 1 & $8 \%$ & $0 \%$ & $13 \%$ & $21 \%$ & $0 \%$ & $0 \%$ & $13 \%$ & $15 \%$ \\
\hline & Product fit/shape & 1 & $7 \%$ & $0 \%$ & $12 \%$ & $20 \%$ & $0 \%$ & $0 \%$ & $12 \%$ & $14 \%$ \\
\hline
\end{tabular}

Fig. 6. Screenshot of spreadsheet used for Phase 3.

Table 5

Results of activity 3.2 .

\begin{tabular}{|c|c|c|c|}
\hline $\begin{array}{l}\text { Combination } \\
\text { number }\end{array}$ & $\begin{array}{l}\text { Combinations of design characteristics [Product } \leftrightarrow \\
\text { Service] }\end{array}$ & $\begin{array}{l}\text { Focus ratings for integration } \\
\text { (FRI) }\end{array}$ & $\begin{array}{l}\text { Feasibility for increased integration given by } \\
\text { designers }\end{array}$ \\
\hline 1 & Type of material $\leftrightarrow$ Customizability & $27 \%$ & Yes \\
\hline 2 & Amount of material $\leftrightarrow$ Customizability & $24 \%$ & Yes \\
\hline 3 & Number of components $\leftrightarrow$ Customizability & $23 \%$ & Yes \\
\hline 4 & Product fit/shape $\leftrightarrow$ Customizability & $20 \%$ & Yes \\
\hline 5 & Type of material $\leftrightarrow$ Modularity & $21 \%$ & Yes \\
\hline 6 & Dryness $\leftrightarrow$ Customizability & $21 \%$ & Yes \\
\hline
\end{tabular}


impacts over the lifecycle of EO requires collaboration from all the relevant actors. This caters to the specific characteristics of a PSS. Based on the "hotspots" indicated by the previous phases, following conceptual design changes are recommended to be incorporated in the new conceptual redesigned offering (RO), as an illustration. Some of these concepts are inspired by the actual practices of the case company, for example, carried out in pilot cases (see Willskytt and Tillman, 2019). Two design changes based on results derived from Phases 1 and 2 (see Sections 4.4 and 4.5) are as follows:

A. The product design characteristic type of material in the product component absorption pads of the products is recommended to be changed to more bio-based and less fossil-based material in the RO, in line with Willskytt and Tillman (2019).

B. The service design characteristic customizability for the service components information is recommended to be systematically redesigned and the following concepts are suggested by the authors to facilitate the redesign: The service activity can include detailed information provision (service component), for instance, in the form of guidelines or handbooks to guide the nursing home personnel or the users themselves (informational output), to collect more information regarding the user's body size, incontinence degree (frequency, quantity and type of incontinence), health status (bedridden or not) and personal preference of the users (informational input). It is also recommended to introduce a database (i.e., web or mobile-based application) to systematically provide and collect the stated informational inputs and outputs, to and from the nursing home and users directly. The database can be used to create dedicated user (i.e., elderly home patients) profiles, which collect the stated information and other data regarding current incontinence products in use by the specific user, on a regular basis. Based on this information, the case company can effectively provide specific products needed by each user or track their current product use.

The concepts for redesign suggested in Design Change B can influence several product design characteristics. The results of Phase 3 (see Table 5, Section 4.6.2) point out the possibilities for integrating combinations of six product design characteristics with the service design characteristics customizability and modularity, which together have a high influence on the design requirements from a lifecycle perspective. Potential design changes that can be introduced in these product design characteristics, as a result of concepts for redesign introduced in Design Change B, are presented in Appendix E. These design changes refer to customized and modular changes in the offering (type, size, quality of the product or its related service) provided to the end-users during service provision and not changes to the design of the product prior to manufacturing. These design changes for the six combinations can increase the integration between the respective product design characteristics, and service design characteristics customizability and modularity, which can potentially influence the design requirements in a combined manner.

\subsubsection{Assessment of the suggested conceptual design changes}

To assess the outcomes of the application of LFD, the conceptual design changes recommended in Section 4.7.1 are assessed by building upon a similar set of design changes assessed with an LCA in Willskytt and Tillman (2019). The article made a new investigation of, among other things, the environmental impact and resource use implications of changing the type and amount of SAP material to fluff-based material in the absorption pads and of introducing measurement services that were provided to ensure that the correct incontinence products were used for each patient at a studied ward at an elderly home.

Building upon Willskytt and Tillman (2019), in this study, the influence of conceptual changes to the product design characteristic type of material by replacing SAP with fluff in the absorbing core of the absorption pad (based on Design Change A). Also the influence of systemic conceptual design changes to service design characteristic customizability by introducing measurement services (based on Design Change B) and partly modularity of the service component information, on the different product design characteristics type and amount of material, number of components and product fit/shape (based on the systemic design changes a, b and $c$ elaborated in Appendix E), were investigated to assess the suggested RO. Fig. 7 shows the normalised LCA result for the RO compared to EO, considering the percentage contribution from the different parts of the lifecycle.

For GWP and FRD, the impacts seem to have decreased almost by $20 \%$ for the conceptual RO with respect to EO. The impact on land use, however, was unchanged. This can be explained by two factors: first, the measurement service (Design Change B) aimed at matching characteristically different users with the appropriate products (products with the right size and the right absorption capacity). This design change resulted in the provision (and subsequently use) of products with smaller sizes for several users in the $\mathrm{RO}$, in comparison to the products provided to the same users in the EO. Consequently, products with lower absorption capacity could be used in RO, which significantly reduced the material usage. Second, the redesign of the products (Design Change A) meant that they ended up with a lower proportion of fossil-based material and a higher proportion of renewable material. Consequently, the combinations of Design Changes A and B meant that the overall use of renewable material (which is a major contributor to land use impact category), was ultimately unchanged between RO and EO.

The evident reductions in impacts related to GWP and FRD indicate that RO has the potential to be more environmentally benign than the product-centric EO. The conceptual design changes in the RO can be sourced to the decisions of the designers to address the hotspots identified by the outcomes of the application of the design support. This confirms the potential of the navigator to support designers in the redesign of EOs towards PSSs with reduced environmental impacts.

\subsubsection{Feedback from the case company}

A semi-structured interview was carried out with the participants of the workshop to collect feedback regarding the utility of LFD (see Appendix F for more details). The obtained redesign recommendations were considered to be useful by the case company. Design Change A was acknowledged to be immediately feasible and useful in reducing environmental impacts. The other recommendations for systemic design changes ( $\mathrm{B}$ and $\mathrm{a}-\mathrm{c}$ in Appendix E) were acknowledged as steps in the right direction and corroborated

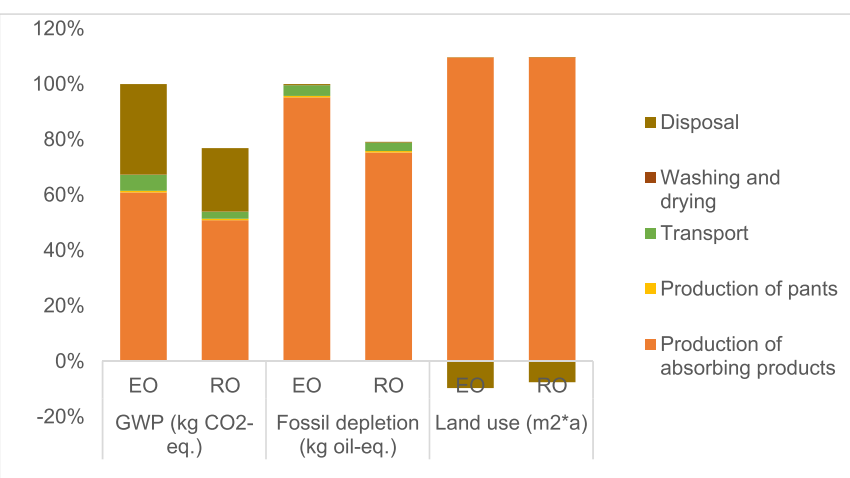

Fig. 7. Normalised impact assessment result for the selected impact categories global warming potential, fossil depletion and land use for RO (redesigned offering) compared with EO (existing offering). 
their opinion that the key to reducing the environmental impacts of their offering across its lifecycle is to provide the right type of product to the right user through the means of service activities.

However, they pointed out certain practical challenges for realizing such a transition towards a PSS in relation to the suggested systemic design changes, such as lack of access to updated user data, ownership of data, and organizational and dynamic nature of user requirements. Since the data is dynamic in nature and includes highly sensitive health-related information of the users of the offering, it would pose a significant challenge for the case company to access and subsequently use it on a consistent basis. Furthermore, the interviewees reported that the organization is predominantly a product-centric manufacturing and retail organization. The suggested service-oriented systemic design would require significant restructuring of several issues on an organizational scale such as business model and supply chain design.

The following strengths of the design navigator were pointed out by the interviewees: i) the novel list of service characteristics was found to be helpful to systematically design and articulate their service offerings, ii) the detailed procedure to apply the design navigator offered them a structured way to redesign, iii) it allowed them to facilitate collaboration with different actors in a structured manner during redesign, iv) the procedure to introduce environmental requirements during the early stages of redesign was found useful to reduce environmental impacts, and v) the potential for the outcomes of the research to be used as a pedagogic tool was highlighted.

\section{Discussions}

To bridge the knowledge gap identified in Section 2, this article presented a generic design navigator LFD that was carefully catered to aid the efforts towards the design of a PSS based on its important inherent characteristics (see Section 2) and successfully applied it in an industrial case study. The research design of the article was based on the principles of the ADR method (Sein et al., 2011). The application has illustrated that the LFD can effectively and efficiently aid designers in the task clarification stage, during the conceptual redesign of an existing product-centric industrial offering (i.e., incontinence products) towards an environmentally benign PSS. Although this application assessed the potential environmental impacts of the concepts of RO that were generated using the navigator, these concepts were not subject to an assessment by the end-users or customers of the offering. However, the assessment did capture the perceived utility of the navigator from the point of view of the collaborating case company, who represents the intended class of recipients of the LFD. Thus, the LFD is expected to be applicable to the redesign of other existing product-oriented industrial offerings in the manufacturing industry. Specifically, the contributions of this article can be broken down as follows:

- The use of LCA results (of the EO being redesigned) as an information input in Phase 0 (see Section 3.2.2) allows the PSS designers to apply a lifecycle perspective while collecting empirical information regarding environmental impacts of the EO. The novel procedure for requirements elicitation (see Activity 1.1 in Section 3.3.1) allows designers to seamlessly derive and relatively prioritize both customer and the environmental design requirements (sourced from the LCA). Such a procedure is not evident in the extant literature and is useful to further advance ecodesign practices. Further, the use of multiple weighting methods (in Formulas [3] and [4]) to identify and select relevant impact categories in the form of environmental requirements that should be addressed during the redesign, is found to be important. By combining different weighting methods that build on different principles for valuing the environment and thus by putting different weights to different impact categories, the risk of missing relevant environmental considerations is reduced.

- Note also that a dominance analysis (see Sections 3.3.1 and 4.3.2), that is, an analysis of what stages in the lifecycle contribute the most to the selected impact categories, is necessary to identify how environmental issues can be approached and potentially designed out with relevant changes to product and service design characteristics (i.e., input to Activity 1.3; see Sections 3.3.3 and 4.4.3).

- The generic list of service design characteristics (see Table 1 in Section 3.3.2) is scientifically new. It is also useful in practice, as it guides the designers to derive service design characteristics (existing or potential) during its redesign to a PSS, even when the EO has few service elements or when the designers have little experience in service design.

- The use of the modified QFD-based matrices and the proposed transparent procedures in Phases 1 and 2 (see Sections 3.3.3 and 3.4.2) is especially useful in practice because it facilitates crossfunctional collaboration by allowing environmental specialists, product designers, and service designers to be navigated to the intended goal.

- The novel procedure for determining FRI in Phase 3 (see Section 3.5) allows the designers to systematically prioritize the integration of certain combinations of product and service design characteristics out of a large number of potential alternatives (as illustrated in Section 4.6). This prioritization is based on the potential exchangeability and the combined impact of the respective product and service design characteristics on the prioritized design requirements. To the best of the authors' knowledge, there is no similar extant procedure in the state of the art that can provide this kind of support, even though it is crucial for realizing the effective and efficient design of a PSS.

These contributions respond to the reflection made by Ullman (2002) regarding the requisite support for designers: "Often designers do whatever is easiest, not what will lead to the best decision ... Much time is wasted making poor decisions". This reflection might have already been addressed by advanced practice in some areas but seems to be valid with contemporary PSS design in industry (Matschewsky et al., 2018). The methodical gap to systematically support designers in the redesign of existing offerings towards a PSS with reduced environmental impacts (using quantitatively grounded empirics) is bridged by the contributions of this article. Below, a few limitations of the proposed design support and future research directions are discussed.

The novel procedure for requirements elicitation (Activity 1.1, Section 3.3.1) has a few limitations in the form of the following systematic and built-in biases.

- Systematic bias: The use of multiple weighting methods in Formulas [3] and [4] might result in the consideration of a different number of impact categories in the respective methods. If a relatively higher number of impact categories relevant to the system in focus are considered in a specific weighting method, then these impact categories will tend to have relatively lower weights than in another weighting method with relatively fewer impact categories considered. Although this issue could be seen as a systematic bias, the inclusion of these formulas is deemed necessary as different weighting methods are generally built on different principles for valuing the environment, thus allowing the consideration of multiple viewpoints. 
- Built-in bias: Additionally, there may be a built-in bias in this procedure that could unfairly reduce or increase the relative importance ratings of environmental requirements in relation to the customer requirements. If the outcomes of Formulas [3] and [4] include a relatively higher number of environmental requirements rated as more important than that of the rated customer requirements (the outcome of Formula [1]), then the environmental requirements may receive relatively lower importance ratings than the customer requirements. This can, of course, happen the other way around for customer requirements as well. Thus, to mitigate this bias, Formula [6] is introduced, which facilitates the normalization or relative prioritization of both environmental and customer requirements.

It should be noted that the design navigator was applied in the case company in collaboration with the researchers who have extensive expertise in LCA and PSS design. Hence, there is a risk that companies (even this case company) may not be capable of successfully using this design navigator without the support of such experts. Since such expertise is a prerequisite for the successful application of this specific design navigator, this support could be more appropriate for companies that have expertise in ecodesign and are looking to further advance their practice. Furthermore, LCA of EOs and ROs that are complex systems like PSSs might introduce several challenges (see Kjaer et al., 2016) that are outside the scope of this article (see a recent work by Kjaer et al. (2018) to address the potential challenges). Design support, to increase the chances of successful ecodesign in industry, should include both tools (navigators such as LFD or similar methods) and the expertise to use such tools. The combined availability of these two elements as a support for ecodesign is less researched in contrast to the development and application of design support tools or methods as such and therefore deserves more attention.

Investigating the performance of an entire design process (including cost-benefit analysis) in relation to the employed design navigator for environmental sustainability is beyond the scope of this article. However, it is indeed an important research topic, and interested readers are invited to carry out such an investigation building upon earlier works (e.g., Rodrigues et al., 2016). Further, it is important to note that the transition of the EO towards a PSS will introduce several other complexities, such as required changes in the business model and supply chain design, among other aspects (as confirmed by the case company in Section 4.7.3.). These issues concerning the dependency between designing and business models are not clearly addressed in the extant literature. Thus, it could be an important area for future research to provide more holistic and effective support for the transition of manufacturing companies towards the development and provision of environmentally benign PSSs.

\section{Conclusions}

This article presented a design navigator titled lifecycle-oriented function deployment (LFD), which can support designers to redesign existing industrial offerings into a PSS with less environmental impacts. It is applicable in the early stages of redesign (i.e., task clarification) and allows the users to efficiently and effectively pinpoint the hotspots to be addressed to make the transition towards a PSS with reduced environmental impacts. It uses a combination of LCA and QFD, while also introducing a novel procedure to identify potential hotspots for integrating product and service design characteristics from a lifecycle perspective. The navigator requires the involvement and collaboration of environmental and market experts, as well as product and service designers. The application of the method in an industrial case involving incontinence products confirmed its potential to offer the required support for the designers. Future work may involve the development of design navigators to aid the designers in the later stages of redesign towards a PSS with reduced environmental impacts.

\section{CRediT authorship contribution statement}

Abhijna Neramballi: Conceptualization, Methodology, Validation, Formal analysis, Investigation, Writing - original draft, Writing - review \& editing, Visualization, Project administration. Tomohiko Sakao: Conceptualization, Methodology, Validation, Formal analysis, Investigation, Writing - original draft, Writing - review \& editing, Project administration, Supervision. Siri Willskytt: Conceptualization, Methodology, Validation, Formal analysis, Investigation, Writing - original draft, Writing - review \& editing. Anne-Marie Tillman: Conceptualization, Methodology, Validation, Formal analysis, Supervision, Funding acquisition.

\section{Declaration of competing interest}

The authors declare that they have no known competing financial interests or personal relationships that could have appeared to influence the work reported in this paper.

\section{Acknowledgements}

This research is supported by the Mistra REES (Resource-Efficient and Effective Solutions) program funded by Mistra (The Swedish Foundation for Strategic Environmental Research) in Sweden (grant number DIA 2014/16) and the Chalmers Area of Advance Production. The authors would like to acknowledge the industrial case company for its participation and valuable contribution to this research. Special thanks to Mattias Lindahl of Linköping University for taking the time to review for improvement of an earlier draft for this article. Finally, the authors would like to acknowledge the efforts of the anonymous reviewers in improving this article.

\section{Appendices A-F. Supplementary data}

Supplementary data to this article can be found online at https://doi.org/10.1016/j.jclepro.2020.124074.

\section{References}

Akao, Y., 1990. QFD: Quality Function Deployment - Integrating Customer Requirements into Product Design, 1990.

Allais, R., Gobert, J., 2016. A multidisciplinary method for sustainability assessment of PSS: Challenges and developments. CIRP J. Manuf. Sci. Technol. 15, 56-64. https://doi.org/10.1016/j.cirpj.2016.04.007.

Alting, L., Legarth, J.B., 1995. Life cycle engineering and design. Ann. CIRP 44, 569-580. https://doi.org/10.1016/S0007-8506(07)60504-6.

Amaya, J., Lelah, A., Zwolinski, P., 2014. Design for Intensified Use in Product Service Systems Using Life-Cycle Analysis, 25, pp. 280-302. https://doi.org/ 10.1080/09544828.2014.974523.

Arai, T., Shimomura, Y., 2005. Service CAD system - evaluation and quantification. CIRP Ann. - Manuf. Technol. 54, 463-466. https://doi.org/10.1016/S00078506(07)60145-0.

Aurich, J.C., Fuchs, C., 2004. An approach to life cycle oriented technical service design. Cirp Ann. Technol 53 (1), 151-154. https://doi.org/10.1016/s00078506(07)60666-0.

Aurich, J.C., Fuchs, C., Wagenknecht, C., 2006. Life cycle oriented design of technical Product-Service Systems. J. Clean. Prod. 14, 1480-1494. https://doi.org/10.1016/ 
j.jclepro.2006.01.019.

Baines, T.S., Lightfoot, H.W., Evans, S., Neely, A., Greenough, R., Peppard, J., Roy, R., Shehab, E., Braganza, A., Tiwari, A., Alcock, J.R., Angus, J.P., Basti, M., Cousens, A., Irving, P., Johnson, M., Kingston, J., Lockett, H., Martinez, V., Michele, P., Tranfield, D., Walton, I.M., Wilson, H., 2007. State-of-the-art in product-service systems. Proc. Inst. Mech. Eng. Part B J. Eng. Manuf. 221, 1543-1552. https:// doi.org/10.1243/09544054JEM858.

Baumann, H., Tillman, A.-M., 2004. The Hitch Hiker's Guide to LCA.

Bey, N., McAloone, T., 2006. From LCA to PSS - making leaps towards sustainability by applying product/service-system thinking in product development. In: Proceedings of the 13th CIRP International Conference on Life Cycle Engineering. LCE 2006, pp. 571-576.

Böckin, D., Tillman, A.-M., 2019. Environmental assessment of additive manufacturing in the automotive industry. J. Clean. Prod. 226, 977-987. https:// doi.org/10.1016/j.jclepro.2019.04.086.

Boehm, M., Thomas, O., 2013. Looking beyond the rim of one's teacup: a multidisciplinary literature review of product-service systems in information systems, business management, and engineering \& design. J. Clean. Prod. 51, 245-250. https://doi.org/10.1016/j.jclepro.2013.01.019.

Booker, J., 2012. A survey-based methodology for prioritising the industrial implementation qualities of design tools. J. Eng. Des. 23, 507-525. https:// doi.org/10.1080/09544828.2011.624986.

Borgianni, Y., Rotini, F., 2015. Towards the fine-tuning of a predictive Kano model for supporting product and service design. Total Qual. Manag. Bus. Excel. 26, 263-283. https://doi.org/10.1080/14783363.2013.791119.

Bowen, G.A., 2009. Document analysis as a qualitative research method. Qual. Res. J. 9, 27-40. https://doi.org/10.3316/QRJ0902027.

Chang, D., Lee, C.K.M., Chen, C.H., 2014. Review of life cycle assessment towards sustainable product development. J. Clean. Prod. 83, 48-60. https://doi.org/ 10.1016/j.jclepro.2014.07.050.

Doultsinou, A., Roy, R., Baxter, D., Gao, J., Mann, A., 2009. Developing a service knowledge reuse framework for engineering design. J. Eng. Des. 20, 389-411. https://doi.org/10.1080/09544820903149354.

Easton, F.F., Pullman, M., 2001. Optimizing service attributes: the seller's utility problem. Decis. Sci. J. 32, 251-275. https://doi.org/10.1111/j.1540-5915.2001.tb00960.x.

Fargnoli, M., Costantino, F., Di Gravio, G., Tronci, M., 2018. Product service-systems implementation: a customized framework to enhance sustainability and customer satisfaction. J. Clean. Prod. 188, 387-401. https://doi.org/10.1016/ j.jclepro.2018.03.315.

Fargnoli, M., Sakao, T., 2017. Uncovering differences and similarities among quality function deployment-based methods in design for X. Benchmarking in different domains 29, 690-712. https://doi.org/10.1080/08982112.2016.1253849.

Geum, Y., Park, Y., 2011. Designing the sustainable product-service integration: a product-service blueprint approach. J. Clean. Prod. 19, 1601-1614. https:// doi.org/10.1016/j.jclepro.2011.05.017.

Gliatis, V., Minis, I., 2007. Service attribute-process matrix: a tool for designing and managing services. Proc. - ICSSSM'06 2006 Int. Conf. Serv. Syst. Serv. Manag. 2, 1350-1356. https://doi.org/10.1109/ICSSSM.2006.320705.

Goedkoop, M., Heijungs, R., Huijbregts, M., Schryver, A. De, Struijs, J., Zelm, R. Van, 2009. ReCiPe 2008- A life cycle impact assessment method which comprises harmonized category indicators at the midpoint and the endpoint level/Report I:Characterisation, Ministerie van Volkshuisvesting, Ruimtelijke ordening en Milieubeheer. Den Haag, Netherlands. https://doi.org/10.1029/2003jd004283.

Hauschild, M., Potting, J., 2015. Spatial differentiation in Life Cycle impact assessment-The EDIP2003 methodology. Environ. Times 80 news.

Hauschild, M.Z., Goedkoop, M., Guinée, J., Heijungs, R., Huijbregts, M., Jolliet, O., Margni, M., De Schryver, A., Humbert, S., Laurent, A., Sala, S., Pant, R., 2013. Identifying best existing practice for characterization modeling in life cycle impact assessment. Int. J. Life Cycle Assess. 18, 683-697. https://doi.org/ 10.1007/s11367-012-0489-5.

ISO, 2006. Environmental Management-Life Cycle Assessment-Principles and Framework, 14040: 2006 (London).

ISO, 1997. ISO 14040: Environmental Management-Life Cycle Assessment-Principles and Framework.

Itsubo, N., 2015. Chapter 15 - weighting. In: Hauschild, M.Z., Huijbregts, M.A.J. (Eds.), Life Cycle Impact Assessment. Springer Netherlands.

Janssen, M., Svanström, M., Arvidsson, R., 2017. Cross-correlation between impact categories in LCAs of forest biomass-based products. In: 9th Biennial Conference of the International Society for Industrial Ecology (ISIE).

Kjaer, L.L., Pagoropoulos, A., Schmidt, J.H., McAloone, T.C., 2016. Challenges when evaluating product/service-systems through life cycle assessment. J. Clean. Prod. 120, 95-104. https://doi.org/10.1016/j.jclepro.2016.01.048.

Kjaer, L.L., Pigosso, D.C.A., McAloone, T.C., Birkved, M., 2018. Guidelines for evaluating the environmental performance of Product/Service-Systems through life cycle assessment. J. Clean. Prod. 190, 666-678. https://doi.org/10.1016/ JJCLEPRO.2018.04.108.

Kjaer, L.L., Pigosso, D.C.A., Niero, M., Bech, N.M., McAloone, T.C., 2019. Product/ service-systems for a circular economy: The route to decoupling economic growth from resource consumption? J. Ind. Ecol. 23, 22-35. https://doi.org/ $10.1111 /$ jiec.12747.

Lacasa, E., Santolaya, J.L., Biedermann, A., 2016. Obtaining sustainable production from the product design analysis. J. Clean. Prod. 139, 706-716. https://doi.org/ 10.1016/j.jclepro.2016.08.078.

Lam, B., Chen, Y.P., Whittle, J., Binner, J., Lawlor-Wright, T., 2015. Better service design for greater civic engagement. Des. J. 18, 31-56. https://doi.org/10.2752/
$175630615 X 14135446523224$

Leech, B.L., 2002. Asking questions: Techniques for semistructured interviews. PS Political Sci. Polit. 35, 665-668. https://doi.org/10.1017/S1049096502001129.

Lelah, A., Mathieux, F., Brissaud, D., 2011. Contributions to eco-design of machineto-machine product service systems: the example of waste glass collection. J. Clean. Prod. 19, 1033-1044. https://doi.org/10.1016/j.jclepro.2011.02.003.

Li, S., Chen, L., 2010. Pattern-based reasoning for rapid redesign: A proactive approach. Res. Eng. Des. 21 (25). https://doi.org/10.1007/s00163-009-0069-2.

Lindahl, M., 2018. Key issues when designing solutions for a circular economy. In: Designing for the Circular Economy. Routledge, pp. 113-122. M. Charter.

Lindahl, M., Sundin, E., Sakao, T., 2014. Environmental and economic benefits of Integrated Product Service Offerings quantified with real business cases. J. Clean. Prod. 64, 288-296. https://doi.org/10.1016/j.jclepro.2013.07.047.

Manzini, E., Vezzoli, C., 2003. A strategic design approach to develop sustainable product service systems: examples taken from the "environmentally friendly innovation" Italian prize. J. Clean. Prod. 11 (8), 851-857. https://doi.org/10.1016/ S0959-6526(02)00153-1.

Matschewsky, J., Kambanou, M.L., Sakao, T., 2018. Designing and providing integrated product-service systems-challenges, opportunities and solutions resulting from prescriptive approaches in two industrial companies. Int. J. Prod. Res. 56, 2150-2168. https://doi.org/10.1080/00207543.2017.1332792.

Maussang, N., Zwolinski, P., Brissaud, D., 2009. Product-service system design methodology: from the PSS architecture design to the products specifications. J. Eng. Des. 20, 349-366. https://doi.org/10.1080/09544820903149313.

Maxwell, D., Sheate, W., van der Vorst, R., 2006. Functional and systems aspects of the sustainable product and service development approach for industry. J. Clean. Prod. 14, 1466-1479. https://doi.org/10.1016/j.jclepro.2006.01.028.

Muñoz, I., Gazulla, C., Bala, A., Puig, R., Fullana, P., 2009. LCA and ecodesign in the toy industry: case study of a teddy bear incorporating electric and electronic components. Int. J. Life Cycle Assess. 14, 64-72. https://doi.org/10.1007/s11367008-0044-6.

Ramani, K., Ramanujan, D., Bernstein, W.Z., Zhao, F., Sutherland, J., Handwerker, C., Choi, J.-K., Kim, H., Thurston, D., 2010. Integrated sustainable life cycle design: A review. J. Mech. Des. 1332 https://doi.org/10.1115/1.4002308, 0910041-09100415.

Rodrigues, V.P., Pigosso, D.C.A., McAloone, T.C., 2016. Process-related key performance indicators for measuring sustainability performance of ecodesign implementation into product development. J. Clean. Prod. 139, 416-428. https://doi.org/10.1016/j.jclepro.2016.08.046.

Sakao, T., 2007. A QFD-centred design methodology for environmentally conscious product design. Int. J. Prod. Res. 45, 4143-4162. https://doi.org/10.1080/ 00207540701450179.

Sakao, T., Birkhofer, H., Panshef, V., Dörsam, E., 2009. An effective and efficient method to design services: empirical study for services by an investmentmachine manufacturer. J. Internet Manuf. Serv. 2, 95-110. https://doi.org/ 10.1504/IJIMS.2009.031342.

Sakao, T., Lindahl, M., 2015. A method to improve integrated product service offerings based on life cycle costing. CIRP Ann. - Manuf. Technol. 64, 33-36. https://doi.org/10.1016/j.cirp.2015.04.052.

Sakao, T., Song, W., Matschewsky, J., 2017. Creating service modules for customising product/service systems by extending DSM. CIRP Ann. - Manuf. Technol. 66, 21-24. https://doi.org/10.1016/j.cirp.2017.04.107.

Scheepens, A.E., Vogtländer, J.G., Brezet, J.C., 2016. Two life cycle assessment (LCA) based methods to analyse and design complex (regional) circular economy systems. Case: Making water tourism more sustainable. J. Clean. Prod. 114 257-268. https://doi.org/10.1016/j.jclepro.2015.05.075.

Sein, M.K., Henfridsson, O., Purao, S., Rossi, M., Lindgren, R., 2011. Action design research. MIS Q. Manag. Inf. Syst. 35, 37-56. https://doi.org/10.2307/23043488.

Smith, L., Maull, R., Ng, I.C.L., 2014. Servitization and operations management: A service dominant-logic approach. Int. J. Oper. Prod. Manag. 34, 242-269. https://doi.org/10.1108/IJOPM-02-2011-0053.

Song, W., Ming, X., Han, Y., 2014. Prioritising technical attributes in QFD under vague environment: A rough-grey relational analysis approach. Int. J. Prod. Res. 52, 5528-5545. https://doi.org/10.1080/00207543.2014.917213.

Sousa-Zomer, T.T., Miguel, P.A.C., 2017. A QFD-based approach to support sustainable product-service systems conceptual design. Int. J. Adv. Manuf. Technol. 88 701-717. https://doi.org/10.1007/s00170-016-8809-8.

Steen, B., 1999. A Systematic Approach to Environmental Priority Strategies in Product Development (EPS). Version 2000 - General System Characteristics. Gothenburg, Sweden.

Stewart, D.W., Shamdasani, P.N., 1990. Focus Groups: Theory and Practice. Sage Newbury Park, Ca.

Tukker, A., 2015. Product services for a resource-efficient and circular economy - a review. J. Clean. Prod. 97, 76-91. https://doi.org/10.1016/j.jclepro.2013.11.049.

Tillman, A.-M., Svingby, M., Lundström, H., 1998. Life cycle assessment of municipal waste water systems. Int. J. Prod. Dev. 3 (3), 145-157. https://doi.org/10.1007/ BF02978823.

Tukker, A., 2004. Eight types of product-service system: eight ways to sustainability? Experiences from suspronet. Bus. Strat. Environ. 13, 246-260. https:// doi.org/10.1002/bse.414.

Tukker, A., Tischner, U., 2006. New Business for Old Europe: Product Service Development, Competitiveness and Sustainability. Greenleaf Publishing.

Ullman, D.G., 2002. Toward the ideal mechanical engineering design support system. Res. Eng. Des. - Theory, Appl. Concurr. Eng. 13, 55-64. https://doi.org/ 10.1007/s00163-001-0007-4. 
Ulrich, K.T., Eppinger, S.D., 2012. Product design and development. McGraw-Hill, USA.

Vasantha, G.V.A., Roy, R., Lelah, A., Brissaud, D., 2012. A review of product-service systems design methodologies. J. Eng. Des. 23, 635-659. https://doi.org/ 10.1080/09544828.2011.639712.

Vezzoli, C., Ceschin, F., Diehl, J.C., Kohtala, C., 2015. New design challenges to widely implement “Sustainable Product-Service Systems. J. Clean. Prod. 97, 1-12. https://doi.org/10.1016/j.jclepro.2015.02.061.

Vidor, G., de Medeiros, J.F., Fogliatto, F.S., Tseng, M.M., 2015. Critical characteristics for the implementation of mass-customized services. Eur. Bus. Rev. 27, 513-534. https://doi.org/10.1108/EBR-03-2013-0066.

Wang, Y.H., Lee, C.H., Trappey, A.J.C., 2017. Service design blueprint approach incorporating TRIZ and service QFD for a meal ordering system: A case study. Comput. Ind. Eng. 107, 388-400. https://doi.org/10.1016/j.cie.2017.01.013.

Webster, K., 2015. The Circular Economy: a Wealth of Flows. Isle Wight, Ellen MacArthur Found.

Willskytt, S., Tillman, A.-M., 2019. Resource efficiency of consumables - life cycle assessment of incontinence products. Resour. Conserv. Recycl. 144, 13-23.

Zhang, W., Guo, J., Gu, F., Gu, X., 2018. Coupling life cycle assessment and life cycle costing as an evaluation tool for developing product service system of high energy-consuming equipment. J. Clean. Prod. 183, 1043-1053. https://doi.org/ 10.1016/j.jclepro.2018.02.146.

Zheng, X., Pulli, P., 2007. Improving mobile services Design : A QFD approach. Comput. Inf. 26, 369-381. 